\title{
Educators' Experiences Of Implementing The National Curriculum Statement: A Case Study Of Mpumalanga Province (Republic of South Africa)
}

\author{
Tebogo I Mogashoa
}

University of South Africa

\author{
Doi:10.5901/mjss.2014.v5n1p119
}

\begin{abstract}
The move from the old curriculum to an outcomes-based education, presented the educators with challenges. In outcomesbased education there are learning outcomes and assessment standards that should be attained and educators had to change the way in which they were used to assess their learners. Educators have to demonstrate an understanding of learning outcomes, assessment standards as well as assessment strategies. Given the challenges that were associated with the National Curriculum Statement, it was important to find out ways in which these challenges were managed by the educators in the school context. The main research question was: What are educators' experiences in implementing the National Curriculum Statement? The research assisted in bringing educators' opinions, ideas and recommendations in current debates about challenges in implementing the National Curriculum Statement. Though several studies have been made, this research has added to what is currently known. Educators are the key role players through which all aspects of curriculum innovations reach learners. A qualitative research methodology was followed in this research to collect data through interviews and observations. Purposive sampling was used to search for information rich informants. The sampling involved the schools from different socio-economic backgrounds. Data analysis involved identifying similarities and differences, and presenting a discussion of the research. Informants and the Department of Education's permissions were requested for the interviews.
\end{abstract}

Keywords: learning outcomes, assessment standards, integration, promotion, progression, continuous assessment, learner performance, learning programme, work-schedule, lesson plan.

\section{Introduction and Background}

There have been critics of the South African education policies which condemned the National Department of Education for a curriculum that is said to be irrelevant and uninteresting for the majority of the South African learners. Before 1994 the education system in South Africa contradicted world trends by deliberately choosing to serve education needs of only a section of the South African population. The birth of democracy in 1994 led to the establishment of a new dispensation and that led to a need for the democratisation of the education system. The apartheid education system has disadvantaged the majority of South Africans especially the black communities. The situation in the new democracy demanded serious changes in many spheres of life in South Africa especially in education.

Among other things which were proposed by the Government of National Unity (GNU), was a transformational outcomes-based education. This ushered Curriculum 2005 with its emphasis on outcomes-based education. According to Kramer (2006: 1), the introduction of outcomes-based education in South African schools and the advent of Curriculum 2005 marked an exciting transformation of the education system. There was consensus about transforming education in South Africa by different stakeholders in education in order to change the education system and introduce a new curriculum.

The Department of Education has taken a transformative approach to outcomes-based education with emphasis on critical outcomes. Critical outcomes are broad educational goals or a set of skills, attitudes and knowledge that all learners should demonstrate after being exposed to learning and teaching. Curriculum 2005 was also informed by the objectives of the South African Qualifications Authority Act , 1995 (Act 58 of 1995) (RSA,1995: 1) which were to create an integrated national framework for learning achievements, to enhance the quality of education and training, to accelerate the redress of the past unfair discrimination, training and employment opportunities and thereby contribute to the full personal development of each learner and the social and economic development of the nation at large. The government was actually trying to come up with a new education system which would cater for all its citizens regardless of race, culture, gender, creed or religion.

However, the changes in education had an impact on the attitude, morale and performance of educators in 
general. These changes required a paradigm shift on the part of educators. The introduction of outcomes-based education made many demands on both the educators and the education system. Educators had to change the way they used to plan and teach while on the other hand learners had to change the way they used to learn. The new curriculum required that educators should be able to understand and respond flexibly to the challenges of the new approaches to curriculum, methods and strategies.

It was therefore logical and appropriate to revisit the implementation of the National Curriculum Statement. A thorough investigation was done to identify educators' problems in implementing the National Curriculum Statement. This formed the basis on which this study was laid. According to Samuels (2009:1), research is designed to solve a particular existing problem so that there is a much larger audience eager to support research that is likely to be profitable or solve problems of immediate concern. Based on research, management can make intelligent and informed decisions (Moorty 2010:1). It was for that reason that, this research was necessary for education policy makers in realising how teaching and learning is affected by the various education policies. It is hoped that the study will also inform policy makers about problems experienced by educators in the implementation of the National Curriculum Statement. Policy makers and decision-making bodies will use the outputs of this study in shaping the education system in future. Assessment policy can have a negative impact on teaching and learning if not appropriately implemented. The study will also assist in highlighting educators' opinions, ideas and recommendations in current debates about challenges of interpreting and implementing the various education policies on teaching and learning.

The significance would be to serve as a motivating tool for educators to continue improving and equipping the learners with variety of skills and competencies. Drotar (2007:3), states that in order to significant, the research needs to exceed the threshold of current scientific work in a specific area. A research study updates previous researches and its development. The significance of the study should discuss the importance of the proposed research and its relevance. The investigation might be relevant for theory, practice and future research. The research study can enhance the critical and analytical thinking of students, therefore, in most of the institutions small research studies are made as essential component of the syllabus. The research study can give food for thought to the new researchers.

Though several studies on various aspects of education have been made, this research will add to what is currently known. This study is also considered to be important in the sense that it could create interest among researchers and educators to engage in more critical reflection and debate on the implementation of any curriculum. The voices of educators will assist the Department of Education to develop strategies and mechanisms in improving the standard of teaching and learning in schools. The educators are the key role players through which all aspects of education policies pertaining to teaching and learning reach the learners.

\section{Theoretical Frameworks}

Critical Discourse Analysis assisted in investigating educators' knowledge and understanding of the National Curriculum Statement. That then developed deeper and richer insights and exposed the researcher and other stakeholders in education to a broad spectrum of literature and knowledge of the National Curriculum Statement and proposes how issues and challenges can be overcome and mitigated.

According to Bazeley (2007: 41), beginning a project by viewing what is already known on the subject is a well established practice, as it reviews the implications of the relevant theories for the topic, and methods others have used to investigate it. Holy, Arhar and Kasten (2005: 263), state that by reviewing literature, we synthesize multiple dimensions of the topic and deepen our understanding of the contents of our own research. According to Terre Blanch (2007:20), refining a research problem involves identifying a theoretical framework upon which to base the research. It is imperative to state the theories that influenced the research problem as well as the research methods that were used. This study was underpinned by a critical discourse analysis theory in which the researcher expressed his comments or judgements based on written or spoken communications, discussions or conversations with educators and the school management team members. It involved an analysis of the merits and demerits of the implementation of the National Curriculum Statement. It was for these reasons that critical discourse analysis was used as a framework to engage and converse about the research problem and questions of this study.

McGregor (2003:1) sees critical discourse analysis as tools to help members of the profession understand the messages they are sending to themselves and others and to understand the meanings of the words spoken and written by others (www.kon.org/archieves/forum/15-1/mcgregorcda.html). According to Van Dijk (2001: 4), critical discourse analysis primarily studies the way social power abuse; dominance and inequality are enacted, reproduced and resisted by text and talk in the social and political context. Lucke (1996:12), states that critical discourse analysis sets out to 
generate agency among students, teachers, and others by giving them tools to see how texts represent the social and natural world in particular interests and how texts position them and generate the very relations of institutional power at work in classrooms, staffrooms, and policy. Furthermore, Locke (2004:1) argues that language is at the heart of critical discourse analysis. Language is an imperative aspect in teaching and learning as all learning areas / subjects are taught through language. Critical discourse analysis assisted the researcher in analysing how the National Curriculum Statement was affected by the social inequalities in various communities in schools. Critical discourse analysis involves debating or communicating in either spoken or written form. This means that policies are drafted and people should be given the opportunities to be involved in debates and conversations about these policies and in order to do so valuable data generated through research such as this was critical.

Critical discourse analysis does not provide a tangible answer to problems based on scientific research but it enables access to the ontological and epistemological assumptions behind a project, a statement, a method of research, or a system of classification (www.ischool.utexas.ed-palmquis/courses/discourse.htm). Discussions with participants in this study assisted in revealing motivations behind texts. Teaching and learning processes and activities are either in spoken or written form. Educators should have appropriate knowledge of the curriculum by reading about these education policies or by listening to experts' descriptions of these policies.

According to Wodak (2009:31), critical means not taking things for granted, opening up complexity, challenging reductionism, dogmatism and dichotonomies, being self reflective in research, and through these processes, making opaque structures of power relations and ideologies manifest (www.qualitative.research.net/fgs/). The National Curriculum Statement was appropriately and critically analysed and described to enable its effective implementation in schools. The principles associated with the National Curriculum Statement were asserted. Discourse analysis is a qualitative method that has been adopted and developed by social constructionists and the focus is any form of written or spoken language, such as a newspaper article (www.eamonfulture.com/discourseanalysis.html).

Apart from critical discourse analysis as the principal theory, this study was also influenced by teaching and learning theories such as constructivism. The focus was on how knowledge or reality is socially constructed. Barbie and Mouton (2007:17), define constructivism as the theory of knowledge or epistemology that argues that humans generate knowledge and meaning from experiences. Knowledge is not fixed but is constructed, shaped and reconstructed in different social contexts and at different times. The way the National Curriculum Statement was implemented in schools needed to be critiqued so as to come up with alternatives to assist the education system of the country. Being critical does not necessarily mean being negative, but critiques can also be positive. The National Curriculum Statement was analysed and interpreted appropriately.

The main research question was as follows:

\subsection{What were educators' experiences of implementing the National Curriculum Statement?}

In order to address the main question the following sub-questions were identified:

- What strategies are the educators employing to improve learners' skills and competencies in learning effectively?

- How knowledgeable are educators in terms of the language of learning and teaching (LoLT)?

- What are the educators' needs for the successful implementation of the National Curriculum Statement?

- How are educators trained or professionally developed to implement the National Curriculum Statement effectively?

- How are learners progressing from one grade to the other?

\section{Research Design and Methods}

Trochim (2006:1), states that research design provides the glue that holds the research project together and design is used to structure the research, to show all the major parts of the research projects- the samples or groups, measures, treatments or programmes, and methods of assessment- work together to try to address the central research questions. Sridhar (2006:3), defines research design and plan as a conceptual structure, a blueprint, an outline of what the researcher will do and planning as selection of a problem, formulation of the selected problem, formulation of hypothesis, conceptualisation, research plan or design. The research methodology of this study was qualitatively and inductively based. Qualitative method was used to gather information from the different categories of participants on how the National Curriculum Statement was implemented. 
Qualitative research assisted the researcher to investigate how educators implement the National Curriculum Statement. The advantage of this approach is that it provided rich descriptive data as observed by the researcher during the interactions with participants. This method enabled the researcher to capture different experiences of the participants accurately

According to Mugo (2011:5), a population is a group of individuals, persons, objects, or items from which samples are taken for measurements, for example a population of presidents or professors, books or students. Selection of the schools was based on the following criteria:

- $\quad$ The type of the schools

- The learner and educator population and

- The location of the schools.

The target group and population of the study comprised of experienced educators who were teaching grade 4-6 learners, English as First Additional Language (FAL). Only five schools in Mpuluzi circuit of Mpumalanga Department of Education were invited to participate in the study. Each school had three participants. Schools were selected purposefully to the extent that they were regarded as rich informants of knowledge the research intended to gather (Patton, 1990:47.

\section{Data Collection}

According to Voce (2005:6), the primary methods of data collection in qualitative research are observation, interviews and focus group discussion. In-depth formal interviewing was used as the main data collection method. Other data collecting techniques such as Data was also collected through observing and describing what are the experiences of the participants. The researcher interacted with the participants in order to get the most reliable information. To avoid manipulation, the researcher gave the participants equal opportunities to participate in the investigation. The researcher used focus group interviews and individual interviews to collect data. Follow-up sessions were appropriate in the form of structured and unstructured interviews. Focus group interviewing is a carefully planned discussion designed to obtain perceptions on a defined area of interest in a permissive non-threatening environment (Krueger and Cacy 2009:6). This data collection method is actually an open group discussion. The format of this type of group interview is not that of question and answer. The researcher encouraged respondents to use their own terminology in describing their experiences. The reason for this was to allow the data to truly emerge from the respondents.

The researcher spent sufficient time with the participants and observed persistently in order to ascertain validity of information as well as by triangulation, which is, using more than one method of data collection. To ensure that reliability and validity was ascertained in this critical discourse analysis study, the researcher first pilot-tested the research instruments and used opinions from experts.

\section{Data Analysis and Interpretation}

According to Michelle (2007:3), qualitative data analysis consists of identifying, coding and categorising patterns found in the data. Bradley (2007:5) declares that once the data have been reviewed and there is a general understanding of the scope and contexts of the key experiences under study, coding provides the analyst with a formal system to organise data, uncovering and documenting additional links within and between concepts and experiences described in the data. Plooy (2007:41) defines data analysis as a process of bringing order and structure to the mass of collected data. Discourse analysis usually uses tapes so they can be played and replayed for several people discussing, not individual person specifically. Data analysis and interpretation involved the analysis and interpretation of documents related to the National Curriculum Statement. Data was analysed by selecting, comparing, synthesising and interpreting information to provide explanation. The researcher analysed and interpreted what is the "big picture" of what the participants said and how individual statements from the participants related to what the "big picture" stands for. The researcher used the inductive approach to ensure that the research findings emerged from the frequent, dominant or significant themes inherent in raw data generated. Comparisons were drawn, similarities and differences identified and a discussion of the research presented. Once the data have been generated, the researcher organised the data and discovered the relationships or patterns through close scrutiny of the data. The data was coded, categorised and condensed. The researcher then interpreted and drew meaning from the displayed data. The first step to be taken by the researcher involved data organisation. The process also involved grouping of information, coding information of similar kind and genre. After major topics and sub-topics from the interviews and documents analyses have been identified, data collected was categorised according to the topics and sub-topics. 


\section{Research Findings and Discussion}

The following general questions which were followed by more specific questions were asked to the participants:

\section{1 "What is your general understanding of outcomes-based education and the National Curriculum Statement?"}

Educator $\mathrm{F}$ referred to outcomes-based education as: "It is a continuous process whereby teaching takes place all the time". Educator $\mathrm{C}$ indicated that in outcomes-based education, "concepts are integrated and the teaching is learnercentred". Educator I stated that in outcomes-based education, "learners are given opportunities to learn at their own pace". Educator $\mathrm{H}$ stated that "there is activity-based learning, group work and learners are active participants in the learning process".

None of the educators referred to outcomes-based education according to Spady's definition that outcomes are clear results that have to demonstrate at the end of significant learning experiences and are performances that embody and reflect learner competence in using content, information, ideas and tools successfully. However, educators expressed a very practical view about what constitute outcomes-based education. Educators' understanding of outcomes-based education reflected terminology and some basic concepts used in learning area statements and assessment policies. Based on the literature study and educators' responses, one could conclude that they have a fairly good understanding of what constitutes outcomes-based education.

\section{2 "What are the challenges you experience with outcomes-based education and assessment?"}

Most educators conceded that they encountered problems in developing the learning programmes. Educator $\mathrm{C}$ said, "It is very difficult to differentiate between context and content and every time we attended workshops the department of education officials came with different versions about these concepts." This was a similar view expressed by educator $\mathrm{H}$ who said, "One curriculum implementer said that content is found in the context while the other one put it vice-versa." Educators held the view that the education department should develop a common learning programme for all the schools of the same circuit.

Most educators conceded that they found it difficult to analyse and integrate assessment standards into a work schedule. Educator E stated that, "Assessment standards are so complicated and one finds it difficult to identify what is content in them. Learning outcomes are clear but integration is difficult." This view was also shared by educator A when she said, "We read through these assessment standards but one always find it difficult to come up with a clear interpretation." Educator $\mathrm{F}$ expressed his confidence in identifying the content in the assessment standards by saying, "You must identify what are skills, knowledge and values so that you can decide what is the content in these assessment standards." They held the view that the template for the work schedule should be simplified.

Most educators held the view that some concepts of a lesson plan are not easy to interpret. This view was evident in educator G when she stated that, "The concepts of looking forward to and looking backward at in the lesson plan are really not easy to be accomplished. I always don't know what to write in that column. I have asked for clarity in this regard, but I always don't have a clear answer."

Some educators complained that a lesson plan template is so complicated with concepts that they cannot interpret. Educator $\mathbf{C}$ stated that, "Some of the concepts like planned assessment and assessment activities in the lesson plan are confusing. I don't see any difference because assessment activities are just the same as planned assessment. This is just a repetition of the same information and creates more work for us." All educators held the view that the template for the lesson plan should be simplified.

The interviews revealed educators' concerns in terms of the volume of paper work involved in planning and assessment procedures. Educators indicated that there were so many assessment standards they had to assess learners against. Educator A responded by saying that, "I am teaching four learning areas and expected to do planning in all of them and record assessment. This takes too much time and I end up not teaching learners but busy planning." Educator I expressed similar views when he said, "I must assess learners in all the five learning areas and the large numbers in each class makes it very difficult. When I have to record assessment, it takes me the whole day. This is too much work for us." However, the documents analysed revealed a systematic and consistent recording of learner achievement and progress.

The Intermediate Phase educators conceded that the National Curriculum Statement confused them and had initially caused them frustration and anxiety. Inadequate educator preparation for the implementation of the National 
Curriculum Statement was expressed by educator I as, "The manner in which we were trained is not adequate. We were trained for only one week and we are expected to deliver the goods. There are no enough resources to make implementation easier. This is only easy in those schools in towns and big cities because they have appropriate resources." This was a similar view held by educator D who said, "The people who were conducting workshops were also not clear about some of the aspects of the National Curriculum Statement." All educators interviewed held the view that the quality of educator development in terms of the implementation of the National Curriculum Statement was poorly planned.

Though educators who were interviewed indicated that they attended workshops on the implementation of the National Curriculum Statement, they conceded that a week was inadequate and too basic. Educator C said, "We were given superficial training on the National Curriculum Statement." This was supported by educator G who said, "The training programme was based more on theory than on practice. We were not given practical examples of implementing the National Curriculum Statement in a real classroom situation." This was the response from another educator, "I was very disappointed when facilitators gave different versions of what the difference is between content and context."

Most educators interviewed were not clear about the principles of assessment. Amongst the responses from those interviewed were: Educator $E$, "The National Curriculum Statement is outcomes-based and learners learn independently." Educator A said, "The National Curriculum Statement is outcomes-based and learners can design their own activities and learn at their own pace." Another response by educator F was, "Assessment is continuous and learners do not write tests or examinations." Based on the above responses it was clear that educators did not have a clear understanding of the principles of assessment because no one has made reference to the principles of assessment as outlined in the assessment policy document.

Educators were not clear in their responses with reference to the principles of recording and reporting. Some of the responses received were: Educator F, "I only know that everything learners do in class should be recorded. Reporting is done at the end of the term to show learners achievement." This was the response from educator $\mathrm{H}$, "Reporting is done to show learner progress and achievement. Reporting is done at the end of each term to inform learners of what they have achieved and what they have not achieved." From the above responses, it was clear that educators had a very simplistic understanding of the principles of recording and reporting. None of the educators made reference to principles of recording and reporting as outlined in the National Protocol on Assessment.

Educators complained about lack of resources, both material and human. These were the responses from the educators who were interviewed: Educator $C$, "We don't have textbooks that clearly outline the learning outcomes and assessment standards. We still rely on the old textbooks that we were using." Educator $\mathrm{G}$ also held the similar view, "If the department of education can supply appropriate textbooks that outline these learning outcomes and assessment standards as well as the assessment activities, that will assist us in implementing the National Curriculum Statement. The textbooks that we are using are not appropriate."

Educators complained about the large number of learners in their classrooms. Educator A responded like, "Our learners can behave well and they have respect for their educators. Our major problem is that we have more than 45 learners in each class. This hampers us from attending learners individually." A similar view was expressed by educator $\mathrm{E}$, "It is difficult to keep order during group work because of the numbers of learners in our classes."

From the educators' responses, it was clear that educators had difficulties in developing learning activities that are appropriate to the various learning outcomes. These were some of the responses from the educators who were interviewed: Educator $\mathrm{H}$, "I struggle to create an activity for learners which will assist them to achieve the learning outcomes." Educator D also expressed a similar view, "In our workshops we are not actually assisted on how to develop learning activities that are informed by these learning outcomes."

With regard to outcomes-based assessment, educators conceded that forms of assessment are commonly used in the intermediate phase. Educators also expressed a common view of equating continuous assessment with outcomesbased assessment. Reference was also made to assessing learning outcomes and assessment standards. Some educators also made reference to assessment methods such as per assessment, self-assessment, group assessment, but they put more emphasis on educator assessment. Educators also made mention of forms of assessment in languages such as creative writing, response to text, functional writing and investigation. Most educators expressed their positive views about baseline assessment and that if appropriately applied, it could assist them to determine what learners already know. However, the educators agreed that they usually did not apply baseline assessment. These were some of the views of those who were interviewed: Educator $\mathrm{H}$, "Baseline assessment can assist me to plan learning programmes and learning activities." Educator E also shared the same view when she said, "Baseline assessment can assist if it is done at the beginning of each task, grade or phase. This is the same as the old approach when we spoke of 
testing of prior knowledge. However, we don't usually apply baseline assessment."

Educators had different views about diagnostic assessment. This is how they expressed their views: Educator D, "I think as educators we don't have the necessary skills to apply this kind of assessment." Educator G expressed a different view, "Diagnostic assessment is essential because it assists us to plan assessment activities in a way that even learners who experience barriers to learning are taken into consideration." Educator E expressed her view in this way, "Learners who experience barriers to learning should be send to special schools." From the educators' responses it could be deduced that much needed to be done to make sure that learning and teaching was consistent with outcomes-based education philosophy of inclusivity in education.

When responding to how formative assessment could assist in giving feedback to learners and parents about learner performance, educators had similar views. Educator G, "Learners' performance can be recorded and reported to learners and parents. Learners can be assessed orally, with class works and tests." Educator B expressed similar view, "Learners should be involved in various learning activities and tasks. What learners are doing in class can be formally recorded and tests given." Most educators expressed the view that tests are still important but should form part of continuous assessment. With regard to summative assessment, the educators held the same view that this type of assessment gives an overall picture of learners' progress at a given time. These were some of the responses: Educator A, "Learners should be given tests at the end of each term so that progress can be monitored." Educator $\mathrm{G}$ expressed his views like, "Though learners are assessed continuously, it is important to assess them with many tasks at the end of the year. This will assist us in determining whether learning outcomes have been achieved." From the educators' views, it was clear that learners were assessed through tests at the end of each term and examinations at the end of the year. However educators indicated that the examination was not the only factor to determine whether learners progress to the next grade or not.

Most educators conceded that learners learn differently, thus they are grouped according to ability levels. Educator C said, "I group my learners according to abilities so that I can assist them differently. I do remediation at the end of the day while other groups continue with other activities independently." Educator F expressed her views like, "When learners are grouped according to their ability levels, this gives me an opportunity to attend to learners individually." From these views it showed that educators cared and were aware of learners' ability levels and provision was made for them. This is in accordance with the outcomes-based principle that learners learn at different paces and have different learning styles and therefore may not be assessed at the same time, context and in the same way. Educators should apply different methods, tools and techniques when assessing learners because every learner is unique. The interview also revealed that educators used worksheets, tests and projects for self and peer assessment.

With regard to assessing learning outcomes and assessment standards, most educators expressed their views that they were still assessing against forms of assessment rather than against learning outcomes. These were some of their responses: Educator G, "I assess against forms of assessment such as creative writing and response to text." Educator A said, "I assess learners' progress or achievement against forms of assessment like projects and functional writing." When asked to submit documents they used as guidelines for outcomes-based assessment, most educators referred to departmental guidelines, policies and workshop handouts. The educators complained that in their workshops they received contradicting documents. Educator $\mathrm{C}$ said, "I am responsible for different learning areas and we always get contradicting documents when attending workshops on assessment." On the basis of the responses from the educators as well as an analysis of the documents, one can deduce that educators were not familiar with the documents on outcomes-based assessment.

When asked about portfolio assessment, educators indicated that portfolio requirements were consistent with the requirements stipulated by the schools policies on assessment. Educator B said, "Portfolio assessment includes tests, projects, assignments and worksheets chosen by the learners themselves. The school's policy on assessment highlights some requirements such as managing and accessibility of a portfolio." Educator F said, "Learners should select evidence to be placed in their portfolios. A checklist should be used by both learners and educators to establish whether the portfolio has been kept according to given criteria." Educator $\mathrm{G}$ confirmed that, "Learners' portfolio checklists should have important aspects such as organization and structure, learners' names, grade, date, forms of assessment, index, title page and number of activities." A random analysis of learner portfolios from each grade in the intermediate phase showed contents that were in line with policy requirements, that is, portfolios should be built over a period of time and retained as proof of the development and improvement of learner achievement.

With regard to the recording of learner's progress, educators indicated that they had records of each learner's progress. This was the response from educator G, "We have recording sheets that we designed. We use these recording sheets to record learners' progress." Educator A said, "Some of the curriculum implementers gave us recording sheets, 
but we are not forced to use them. They only serve as guidelines. This was the response from educator I, "We record anything that we are assessing. We spend more time on assessing learners than teaching them." A critical analysis of the recording sheets used by educators revealed that most of them recorded marks for tests. Only a few educators recorded against forms of assessment and learning outcomes.

Educators indicated that the reporting of learners' progress was done by means of written reports. These report cards are sent to parents. This was the response from educator G, "We send report cards to parents at the end of each term. However, only a few parents come to parents meetings where learners' performances are discussed." Educator D also held the same view, "Every term we send report cards to parents but they don't come to discuss their children's performances even when invited." An analysis of the report cards indicated that not much was said about the learning outcomes and assessment standards. The report cards indicated forms of assessment and the levels of achievement. From the responses of educators, one could conclude that there was little communication between educators and parents in terms of learner achievement of the learning outcomes.

Educators who were interviewed expressed lack of support in terms of curriculum management. Educator $E$ said, "The school management team is not fully supporting us on how to implement this curriculum. We don't get clear information especially on how to assess learners." This view was also expressed by educator B, "We encounter problems when departmental officials come for moderation. There are no proper guidelines of what is expected of us." According to the responses made by the educators, curriculum management was still a serious challenge at schools. Most of the educators complained that the school management teams did not attend workshops on curriculum matters.

Educators indicated that they don't meet regularly to discuss curriculum matters. They conceded that they only come together when developing learning programmes and do not usually share ideas on how to implement this curriculum. Educator H said, "We don't get opportunities to share and air our views in terms of the implementation of this curriculum. We are only being informed and expected to implement. We should be given opportunities to participate in curriculum development." Educator $\mathrm{C}$ expressed her view that, "There is lack of team work on the part of the educators. We don't plan together. Everyone does things the way he or she understands." The interviews revealed that educators and school management teams did not promote team work.

Most educators expressed disappointment in term of parental involvement in curriculum matters. Educator $E$ said, "Parents must be involved in the education of their children. However, this is not the case here. Most parents do not attend parents meetings. There is lack of communication on the part of parents about their children's performances. From most educators interviewed one could deduce that parents were invited to discuss their children's performances at schools but they did not respond positively.

\section{Conclusions and Recommendations}

The introduction of Curriculum 2005 and later the National Curriculum Statement was the critical turning point of curriculum transformation in South Africa. The introduction of the National Curriculum Statement had a negative impact on teaching and learning practices as well as the way assessment was done in schools. The educators did not receive adequate and appropriate training for them to be able to implement the new curriculum. There were inadequate resources to make the implementation of the curriculum a success. Most educators lacked appropriate knowledge and skills in developing learning activities as required by the principles of outcomes-based education. Document analysis also revealed educators' inabilities in developing learning programmes, work schedules and lesson plans. Recording of learner achievement was done against forms of assessment instead of been done against learning outcomes and their assessment standards.

The educators should be provided with in-service programmes which can assist them to explore and develop new ideas to make implementation of the National Curriculum Statement easy. Continuous professional educator development should be put in place to assist the educators to cope with new changes of the curriculum. Educators should be given clear content to teach their learners. Guidelines for designing learning and assessment activities should be developed. Educators should be developed on how to assess and record learners' achievement of particular learning outcomes and the assessment standards. Schools should draw programmes in order to assist parents to be actively involved in the education of their children. Given the inadequate training, lack of appropriate teaching and learner support materials and the complexity of the National Curriculum Statement, it would be useful to investigate the skills, knowledge and values that learners acquire when using outcomes-based approach. 


\section{References}

Barbie, E. and Mouton, J. 2006. Research methodology by numbers- a teaching tool. Durban University of Technology.

Bazely, P. 2007. Qualitative data analysis with Nvivo. London: Sage Publications.

Bradley, E.H. et al. 2007. Qualitative Data Analysis for Health Services Research.

Drotor, D. 2007. Thoughts on Establishing Research Significance and Preserving Scientific Integrity.

Holly, M.L.; Arhar, J.M and Kasten, C.W. 2005. Action Research for teachers: Travelling the yellow Brick Road (2nd edition) New Jersey: Pearson Prentice Hall.

Kramer, D. 2006. OBE teaching toolkit: OBE strategies, tools and techniques for implementing C2005.

Krueger, R.A. \& Casey, J. 2009. Successful focus groups: practical guidelines for research (4th edition). Thousand Oaks, CA: Sage.

Locke, T. 2004. Critical Discourse Analysis. London: Cromwell Press

Lucke, A. 1996. Text and Discourse Analysis. New York: American Educational Research Association.

McGregor, S.L.T. 2010. Critical Discourse Analysis: A Primer. Halifax. Mount Saint Vincent University

Michelle, B. 2007. Data Analysis Strategies for Qualitative Research- Research Corner

Moorty, S. 2010. The Significance of research in Business Decision Making.

Mugo, F.W. 2011. Sampling in Research. Thoasand Oaks: Sage Publications

Plooy, G.M. 2007. Communications Research Techniques, Methods and Implications. Juta and Co. LTD.

Samuels, P. 2009. The importance of research- Why we do research

Sridhar, M.S. 2008. Research Methodology: Part 3- Research Design and Plan

Terre Blanche, 2008. Research in Practice: Applied methods for the social sciences. Juda Academy.

Trochim, M.K. 2006. Research Methods Knowledge Base

Van Dijk, T.A. 2001. Critical Discourse Analysis: Sage Publications.

Voce, A. 2005. Handouts for the Qualitative Research Module. Sage Publications

Wodak, R \& Meyer, M. 2009. Methods of Critical Discourse Analysis. Longman. London and New York

www.eamonfulcher.com/discourseanalysis.html .

www.ischool.utexas.ed-palmquis/courses/discourse.htm

www.kon.org/archieves/forum/15-1/mcgregorcda.html

www.qualitative.research.net/fgs/ 
